\title{
A Qualitative Assessment of a Modified Multilevel Converter Topology M2LeC for Lightweight Low-Cost Electric Propulsion
}

\author{
Paul H. Riley1*, Obrad Dordevic ${ }^{2}$, Keith Pullen1, Liliana DeLilo³, Massimo De Giorgio³ \\ ${ }^{1}$ School of Mathematics, Computer Science and Engineering, University of London, London, UK \\ ${ }^{2}$ Department of Electronics and Electrical Engineering, Liverpool John Moore University, Liverpool, UK \\ ${ }^{3}$ School of Engineering, University of Nottingham, Nottingham, UK \\ Email: *paul.riley@city.ac.uk
}

How to cite this paper: Riley, P.H., Dordevic, O., Pullen, K., DeLilo, L. and De Giorgio, M. (2020) A Qualitative Assessment of a Modified Multilevel Converter Topology M2LeC for Lightweight Low-Cost Electric Propulsion. Engineering, 12, 496-515. https://doi.org/10.4236/eng.2020.127035

Received: March 21, 2020

Accepted: July 24, 2020

Published: July 27, 2020

Copyright $\odot 2020$ by author(s) and Scientific Research Publishing Inc. This work is licensed under the Creative Commons Attribution International License (CC BY 4.0).

http://creativecommons.org/licenses/by/4.0/

\begin{abstract}
A Cascade $\mathrm{H}$ Bridge (CHB) is evaluated for both electric vehicle motor traction control and off-vehicle charging against the Power ElectronicsUK $\mathrm{Au}-$ tomotive Challenge for cost and mass for the year 2035. By combining the power electronics with batteries using low-voltage MOSFET transistors in a series cascade arrangement the cost and mass targets could be met 12 years earlier (in 2023 and 20 times lighter if an application specific integrated circuit (ASIC) is used. A $200 \mathrm{~kW}$ peak reference car was used to evaluate cost and mass benefits using four different topologies of power electronics. Vehicle installation is shown to be simplified as only passive cooling is required removing the need for liquid cooling systems and the arrangement is inherently safe; no high voltages are present when the vehicle is stationary. The inherently higher efficiency of $\mathrm{CHB}$ increases vehicle range. The converter with integrated batteries can also behave as an integrated on-board battery charger delivering additional off-vehicle benefits by removing the need for costly external chargers.
\end{abstract}

\section{Keywords}

Power Electronics, Electric Vehicles, Cascaded H Bridge, CHB, Modular Multi-Level Converter, MMC, MLC

\section{Introduction}

For the large-scale acceptance of Electric Vehicles (EVs), certain criteria must be met, not least of which is the cost and mass of the Power Electronics (PE) used in traction, high power ancillaries and fast battery chargers. In the aerospace 
sector, low vehicle mass is also of major importance to electric aircraft. The Power Electronics UK Automotive Challenge [1] has set a number of targets for the specific cost and mass of PE with the year 2035 targets being $\$ 3 / \mathrm{kW}$ and 50 $\mathrm{kW} / \mathrm{kg}$. One of the strategies to meet these targets is system topology. This paper examines the suitability of a Multi-Level Converter (MLC) that house the PE with batteries to gain cost, mass and efficiency benefits over conventional topologies. Chang compared a conventional IGBT inverter with a silicon carbide and multi-level silicon inverter over a simulated driving range [2] and found a $2 \%-3 \%$ improvement in the high rpm range and 3\% - 10\% at lower operating speeds.

MLC in its various guises, Neutral-Point Clamped (or diode-clamped), Cascaded H-bridge, and Flying Capacitor are well-known topologies used for high voltage converters between AC and DC systems. A simplified drawing of the basic Cascaded H Bridge (CHB) concept is shown in Figure 1. The charge distribution in supercapacitors in a Modular-Multilevel-Converter (MMC) configuration was investigated in [3], while in [4] usage of switched individual Lithium cells in a series cascade configuration was proposed. MLC, a well-known topology used for high voltage converters between AC and HVDC systems [5] and more recently have been investigated for vehicle use. The charge distribution in supercapacitors in an MLC configuration was investigated by Mukherjee and Tricoli [3], Figure 2 who also proposed using switched individual Lithium cells

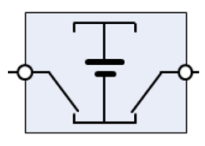

Battery module has two terminals each connected via a two-way switch.

Three states:

Short circuit

Full battery voltage (+ and -) Pulse switch modulating
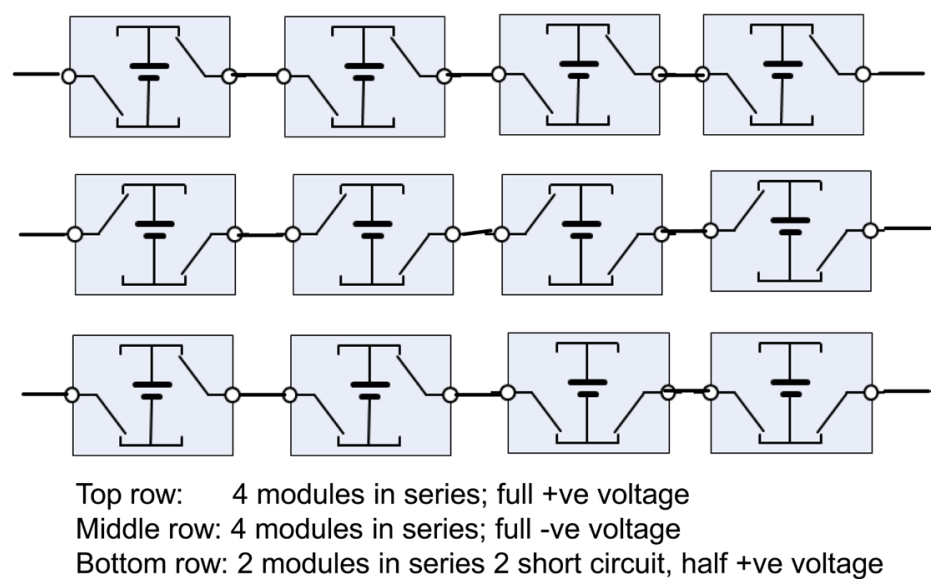

Bottom row: 2 modules in series 2 short circuit, half +ve voltage

Figure 1. Simplified Multi-Level Inverter.

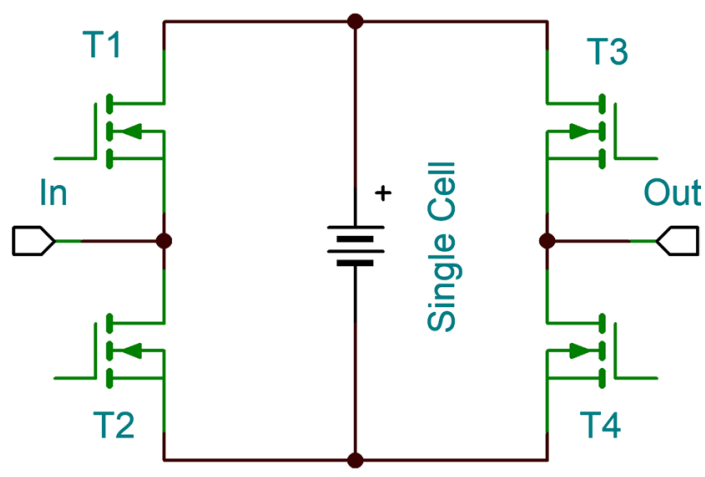

Figure 2. single cell MMC module. 
in a series cascade configuration [4]. Tolbert investigated two MLC topologies, $\mathrm{CHB}$ as a natural fit for all-electric drives and back-to-back diode-clamped (NPC) converter for hybrid vehicles where a source of ac voltage is available for motor control [6] for EVs and later proposed a solution for equalising state of charge between batteries [7]. Chang investigated a non-standard multi-level configuration with PWM signals [8] on what we describe in this paper as the Module In Control (MIC). A simplified drawing of the basic concept of Cascaded H-bridge (CHB) operation is shown in Tolbert proposed using an MLC for motor control [6] and later proposed a solution for equalising state of charge between batteries [7]. Chang improved on the waveform with PWM signals on the Module In Control (MIC) [8].

Until recently, these novel architectures were more expensive than centralised PE systems. However, with recent advances in miniature MOSFETs, distributed architectures are becoming more attractive, although relatively unknown outside academic circles. In this paper, the term Cascaded $\mathrm{H}$ Bridge or CHB is used where the functions of motor control, battery management and battery charging are incorporated in a single set of MLC power electronics and the different functions controlled by software alone.

Two main drivers for electric vehicle manufacturers and hence parameters important to optimise are cost and mass: the topic of this paper.

\section{Road Vehicle Topology}

Road vehicles almost exclusively use "lumped" Power Electronics (PE) and battery modules as shown in Figure 4. The batteries are located in one area, motors in a second and PE in a third. More recent designs have re-located these three elements on the floor and in between the road wheels but the basic topology remains the same. Cooling for all three modules is required usually by a liquid cooling system that adds cost and mass.

Figure 5 shows the modified topological arrangement. The batteries are segmented into 12 sections, three for each motor (assuming 4-wheel drive) and one for each motor phase. Each section comprises a multitude of low-voltage batteries with $\mathrm{PE}$ connected in series and using low-voltage high-current MOSFETs. The PE are assembled using micro-electronic surface mount techniques to reduce costs. Distributing the PE has two installation advantages, firstly, the MLC is more efficient than conventional PE [2] [9] and secondly, being distributed no additional heat management is required; the heat is dissipated through the assembly casing. In a future paper, we will also discuss how advances in Battery technology can also remove the heat management for batteries in such a distributed arrangement.

The CHB Power electronic topology can also function as a battery charger without any additional Power electronics, and charging supply may be single or 3 phase AC, or DC as shown in Figure 6. In the DC configuration, if required, Maximum Power Point Tracking (MPPT) for solar cells can be achieved via a 


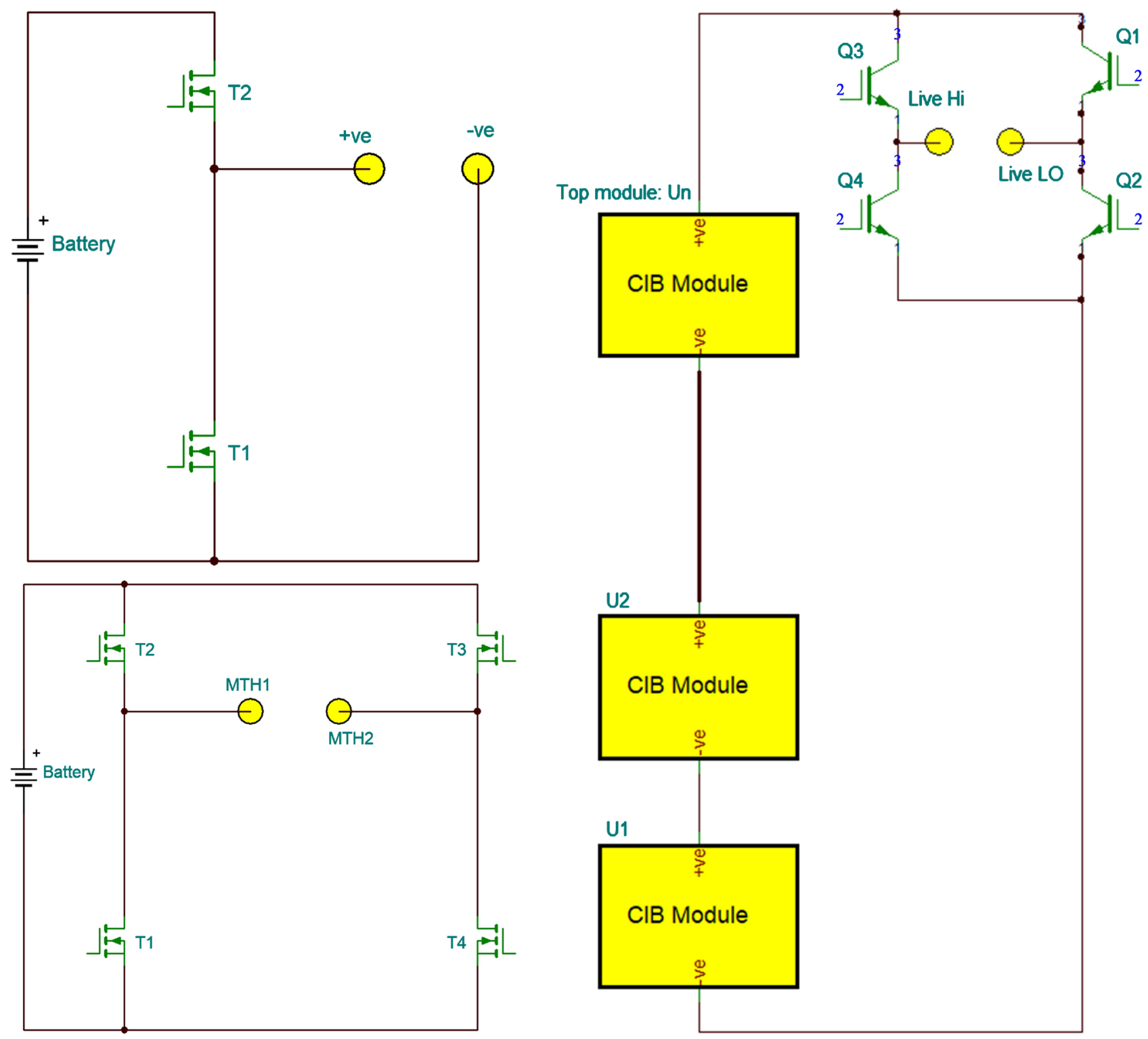

Figure 3. Module options, top left single I-bridge, the full cascade CIB is shown right in a section configuration. Bottom left $\mathrm{H}$-bridge.

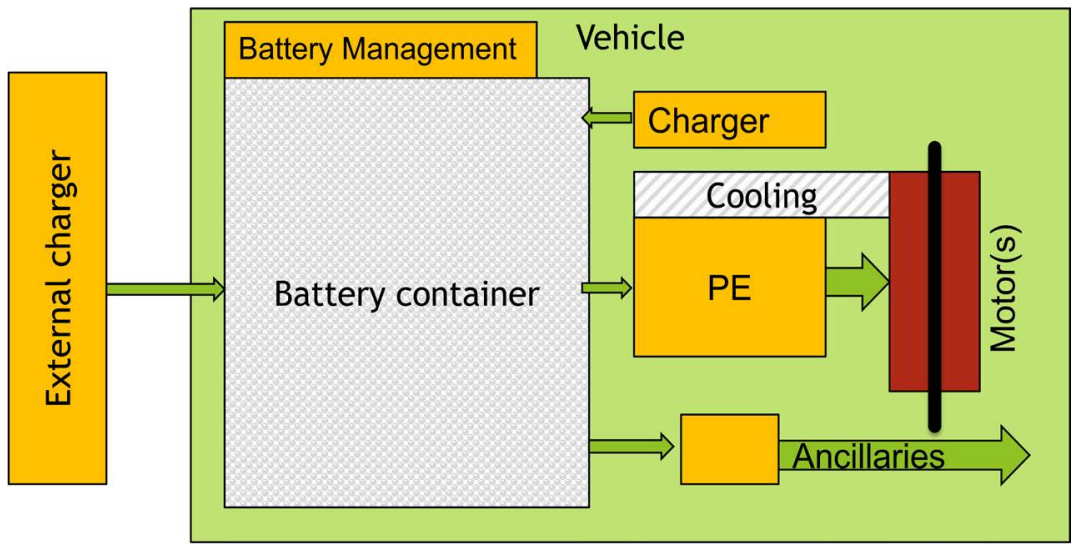

Figure 4. Typical automotive functional EV layout with chargers. 


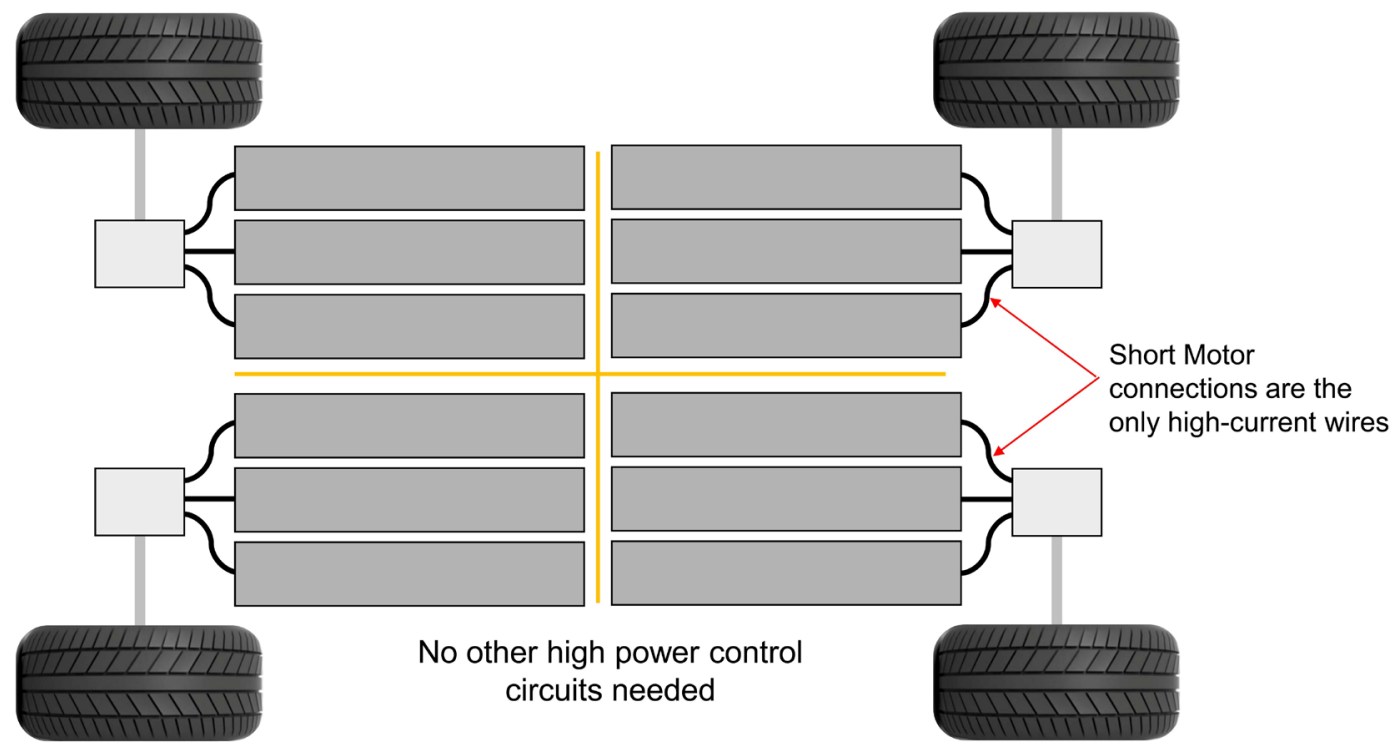

Figure 5. Distributed power electronics EV drivetrain.

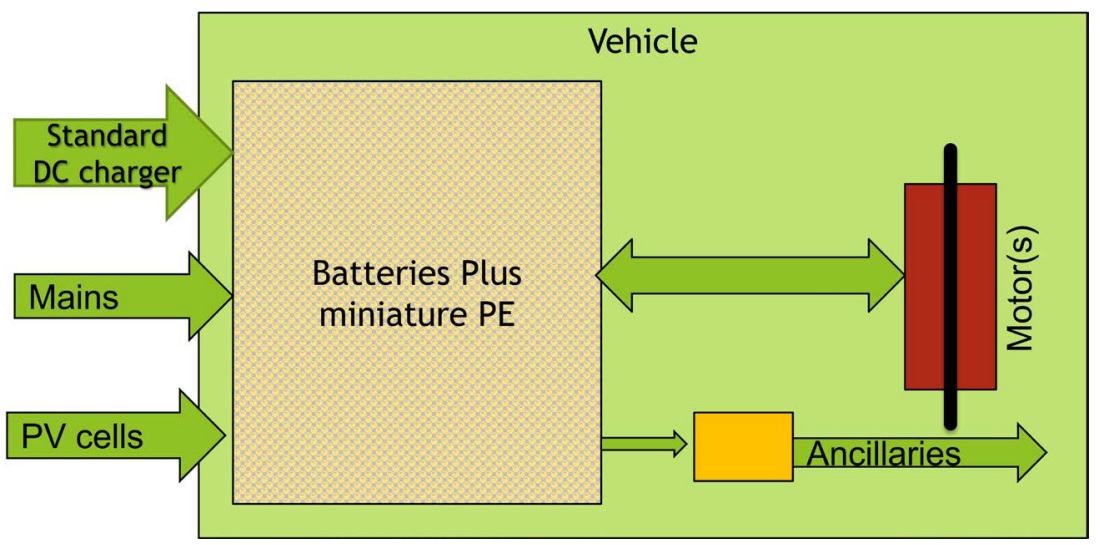

Figure 6. Functional description of $\mathrm{CHB}$.

standard software algorithm [10].

\section{Module Configurations}

The complete reference system used for comparisons is shown in Figure 7 for each of the four motors. One module in each phase controls the motor and receives signals from the vehicle control system. The battery management, vehicle and motor control costs and mass are excluded from the analyses below for a correct comparison with targets.

There are various configurations of PE available in the vehicle. As well as the standard two-level three-phase converter that is used in nearly all EVs nowadays, other multi-level options are summarised in Figure 3. Top left is a single I-bridge of low voltage MOSFETs with the cascade labelled CIB (Cascaded "I" bridge)on the right that control half cycle waveforms, the high voltage IGBT $\mathrm{H}$-Bridge on the top right provides the uni-polar function. Bottom left is a MOSFET H-Bridge used in each cascaded module of Figure 7. 


\section{Traction motor}

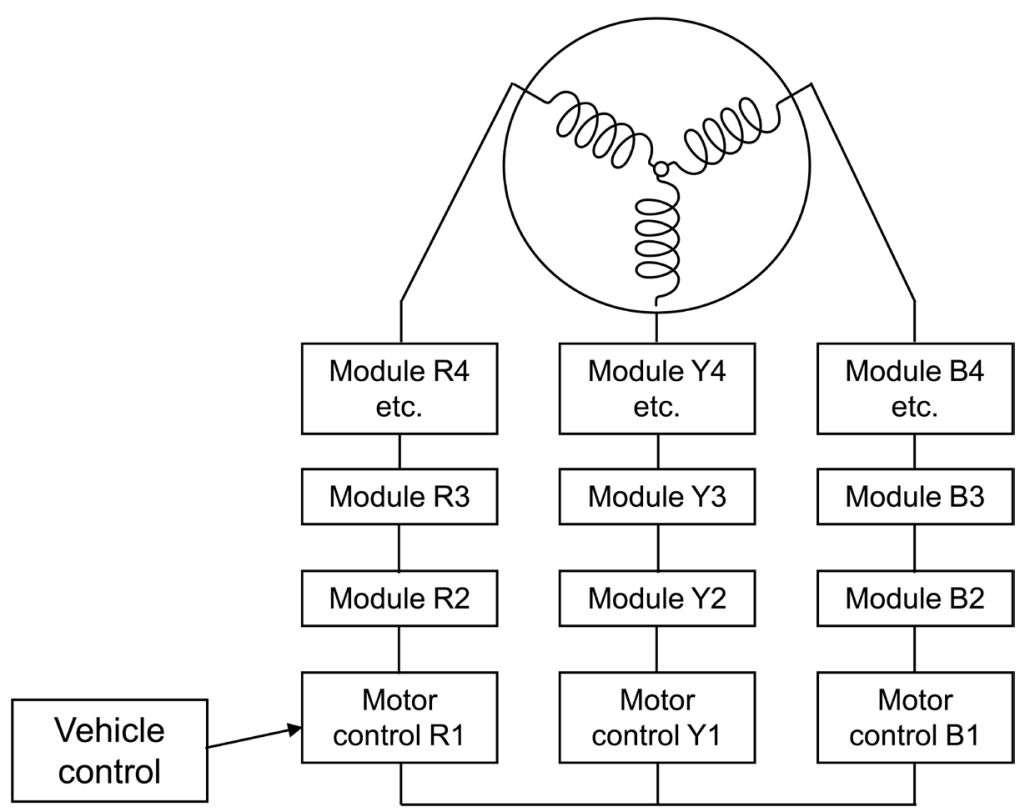

Figure 7. Reference system diagram.

There are a number of benefits with the new topology shown in Figure 7; no high voltages are present when the vehicle is stationary (lower skilled maintenance personnel and first accident responders needed) and better optimisation of cost and mass as shown in the analysis paragraphs.

\section{Theory/Calculation}

\subsection{Reference Design}

For cost, heat flow and mass comparisons, a reference design for a car is chosen with the following characteristics:

1) Peak vehicle power $200 \mathrm{~kW}$;

2) Four-wheel drive;

3) Peak battery voltage per phase of $600 \mathrm{~V}$ (at nominal battery voltage);

4) Giving a battery phase current of $28 \mathrm{~A}$ average.

The design is evaluated at these key points in the operating envelope:

1) Hill climb, where torque is modulated at near zero motor speed;

2) Maximum converter fundamental frequency taken as $250 \mathrm{~Hz}$, (4 ms per rev for single pole);

3) Maximum rate of acceleration, zero to full speed in 10 seconds.

The waveform is closely controlled, with one module operating in pulse width modulation (PWM) designated the Module In Control (MIC). Other modules are either in the "off" (short circuit state) or "on" (full battery voltage) state.

\subsection{Target Costs}

In order to normalise cost calculations, Table 1 shows various configurations. 
Using Li-Ion cells with a nominal $3.6 \mathrm{~V}$ per cell, the bottom two rows of Table 1 shows a how the Power Electronics UK automotive challenge targets for the year 2035 of $50 \mathrm{~kW} / \mathrm{kg}$ and $\$ 3 / \mathrm{kW}$ (peak power) relate to the reference car design and is used as the target costs in subsequent calculations. It should be noted that the higher the number of cells in each module in the cascade, the higher the cost and weight target and the fewer modules needed per vehicle, although the overall cell count is the same. Also note that the table contains some rounding to allow an integer number of cells to be used. The I-Bridge configuration was only analysed for heat flow and rejected because of the power dissipation from the IGBT, as described in section 4 .

\subsection{PE Cost}

As the cost of components changes over time, the baseline for cost comparisons was the EGBP price in quantities shown in the volume column in Table 2 as published in the last quarter 2018 by vendors such as Mouser, On-semiconductors and Digikey and are shown below. Costs are split into three main areas:

1) Power MOSFETs;

2) Balance of micro-electronics components (BEC);

3) Vehicle installation costs.

Table 1. Module cost targets.

\begin{tabular}{ccccc}
\hline $\begin{array}{c}\text { Vehicle PE mass target } \\
\text { Vehicle PE cost target }\end{array}$ & \multicolumn{5}{c}{$\begin{array}{c}\text { kg } \\
£ 500.00\end{array}$} & $\mathbf{1 2}$ & $\mathbf{1 6}$ \\
\hline Cells per module & $\mathrm{V}$ & 28.8 & 43.2 & 57.6 \\
Nominal module voltage & $\#$ & 20 & 13 & 10 \\
Modules per phase & $\#$ & 240 & 156 & 120 \\
Total number of modules & $\mathrm{g}$ & 16 & 24 & 32 \\
Target mass per module & $£$ & $£ 2.00$ & $£ 3.00$ & $£ 4.00$ \\
Target cost per module & & & &
\end{tabular}

Table 2. Comparison of various semiconductors based on the introduced figure of merit $F_{m}$.

\begin{tabular}{|c|c|c|c|c|c|c|}
\hline Device number & Ron Max & Vds & Cost & volume & package & $\mathbf{F}_{\mathrm{m}}$ \\
\hline TPWR8004PL & 0.8 & 40 & $£ 1.25$ & 5000 & Dsop $5.0 \times 6.0 \times 0.73$ & 40.0 \\
\hline IRLS3034PbF & 1.7 & 40 & $£ 0.33$ & 50 & TO220 & $\overline{70.6}$ \\
\hline TPWR6003PL & 0.6 & 30 & $£ 5.00$ & & Dsop $5.0 \times 6.0 \times 0.73$ & 10.0 \\
\hline RFB7534PbF & 2.4 & 60 & $£ 0.90$ & 1000 & TO220, D2Pak & $\overline{27.9}$ \\
\hline NDPL18010B & 3 & 100 & $£ 5.00$ & & TO220 & 6.7 \\
\hline FDMS8050ET30 & 0.65 & 30 & $£ 1.34$ & 1000 & Power 56 & 34.4 \\
\hline IPT015N10N5ATMA1 & 1.5 & 100 & $£ 2.87$ & 250 & PG-HSOF-8 & 23.2 \\
\hline SUM6003 & 3.2 & 80 & $£ 1.45$ & 800 & D2PAK & 17.2 \\
\hline FDD86367 & 3.3 & 80 & $\overline{£ 0.64}$ & 5000 & TO-252-3 & 37.7 \\
\hline NTMFS6H800NT1G & 1.8 & 80 & $£ 2.12$ & 1500 & SO-8FL & 21.0 \\
\hline NVMFS6H801N & 2.7 & 80 & $£ 0.67$ & 1500 & SO-8FL & $\overline{44.2}$ \\
\hline NVMFD5C446NL * & 2.65 & 40 & $\underline{£ 0.61}$ & 1500 & DFN8 & 49.7 \\
\hline
\end{tabular}

Marked ${ }^{\star}$ are two devices in one package. 


\section{De-rating rules}

There is a trade-off between the amount of de-rating, reliability and cost that is outside the scope of this paper.

A derating of $80 \%$ is assumed for the voltage of all semi-conductor devices and a maximum cell voltage of $4 \mathrm{~V}$, i.e. $40 \mathrm{~V}$ devices can work with 8 cells and 80 $\mathrm{V}$ with 16 cells at $80 \%$ derating. Passive components were de-rated at $65 \%$.

\section{MOSFETs}

In order to obtain comparisons across different MOSFET voltages and on resistance, a figure of merit $F_{m}$ is defined:

$$
F_{m}=\frac{V_{D S}}{R_{o n} . £}
$$

where $V_{D S}=$ maximum drain source voltage.

$R_{\text {on }}=$ on resistance at $25^{\circ} \mathrm{C}$ in $\mathrm{m} \Omega$;

$£=$ volume cost as defined in the cost column.

A higher $F_{m}$ is better and means that the device has a lower contribution to system cost.

The $F_{m}$ calculation is shown in Table 2. The volume column shows the "numbers off" for the price shown in the cost column (where known). Neglecting BEC, the IRLS3034PbF has the highest $F_{m}$ at 70.6 but at only $40 \mathrm{~V} V_{D S}$. At the higher voltages, the NVMFS6H801N at an $F_{m}=44.2$ performs best.

The TO220 packages require through-hole mountings increasing assembly and hence BEC costs. The other packages are surface mounted at a lower cost but require a more detailed analysis of heat flow as the copper plane forms an integral part of calculations, as described in later sections.

For the I-Bridge configuration, high voltage transistors are required for the uni-polar H-bridge completion circuit shown in Figure 3. An IGBT gives the best performance for the completion circuit. Table 3 gives a selection of IGBT costs. Each phase would require 4 IGBTs, 48 per vehicle. This option was not taken any further due to the relatively high heat dissipation (see section 4) requiring liquid cooling or expensive air-cooled heat sinks.

\subsubsection{Balance of Electronic Components}

The Balance of Electronic Components (BEC) costs comprise the following:

1) MOSFET drivers (For the topology in Figure 3 right, IGBT drivers are also needed);

2) Micro-controller (if required);

3) Module power supply;

4) Isolated communications circuitry;

Table 3. Comparison of IGBT completion circuit costs.

\begin{tabular}{cccccc}
\hline IGBT & $V_{\text {CEsat }}$ & $V_{\text {CEmax }}$ & Price & Volume & Package \\
\hline FGH40T65UQDF-F155 & 1.33 & 650 & $\underline{£ 2.34}$ & 250 & TO247-3 \\
STGP15H60DF & 1.6 & 600 & $\underline{£ 0.73}$ & 1000 & TO220 \\
\hline
\end{tabular}


5) Bare printed circuit board (PCB) cost per module is estimated at $£ 0.50$ for most options;

6) Assembly costs per module estimated at $£ 0.50$ for most options;

7) Miscellaneous costs calculated as $10 \%$ of the costs of 1 to 6 .

\subsubsection{Module Configuration Options}

The four-module configuration options chosen are summarised in Table 4, overall motor control function of Figure 7 is derived from series connected $\mathrm{H}$ bridges in Figure 3. There are a multitude of components on the market that would accomplish the BEC function. Each option affects the detail of the system design with merits and de-merits and so a high-level analysis using selected options are shown. Finally, an Application Specific IC (ASIC) design is proposed with a set of requirements needed to meet the 2035 targets. Each option is described in more detail in section 4.3.2.2.

The possibility of an MMC [4] configuration, Figure 2 whereby each cell has its own power MOSFETs was explored, however, the current range of MOSFET devices is not optimised for low voltage and hence the costs of this configuration are much higher so the option was not pursued.

\section{Inter-module communication (Coms)}

As the battery negative of each module varies with the output wave form, any communications (coms) between modules must be isolated. There are several methods available to do this.

1) Coms via the power lines;

2) Wireless;

3) Near field;

4) Opto-isolation;

a) For direct PWM control

b) For communications via a serial coms line

5) Capacitor isolation with suitable communications protocol;

6) Silicon dioxide isolation layer.

The choice of coms will affect the suitability of each option and so is included early in the analysis. Coms via the power lines may be subject of a later paper. The various driver isolation performances have been evaluated in these references [11] [12] [13] [14]. In terms of cost and mass: coms $4 a$ would require at

Table 4. Module format options considered.

\begin{tabular}{|c|c|c|c|}
\hline$\#$ & Brief description & Advantages & Disadvantages \\
\hline $\mathrm{O} 1$ & $\begin{array}{l}\text { Local current control, } \\
\text { central feedback }\end{array}$ & Simple, low bandwidth coms & Unsuitable for larger motors \\
\hline $\mathrm{O} 2$ & Centralised motor control & Simpler to design & High bandwidth coms required \\
\hline O3 & $\begin{array}{l}\text { Full motor control in each } \\
\text { module }\end{array}$ & Lowest bandwidth coms* & $\begin{array}{l}\text { High power micro-controller } \\
\text { needed in each module }\end{array}$ \\
\hline $\mathrm{O} 4$ & ASIC & Very low production cost & High development cost \\
\hline
\end{tabular}

${ }^{*}$ Coms $=$ the method of communications considered. 
least 2 wires per module from the central controller to each module; 24 in total adding to vehicle installation cost and was not considered further for a production version. The minimum coms cost is dependent on the BOC chosen and is dealt with in each option below.

\section{Option $\mathrm{O} 1$}

An example of an $\mathrm{O} 1$ implementation is shown in Figure 8. Coms are very low bandwidth comprising Module in command (MIC), Voltage (V) and frequency $(\mathrm{F})$ demand.

Control can be performed by devices such as the MC33033 (normally used for "brushless DC" motors), have a high level of integration and the ability to drive High and Low side 3 phases $\mathrm{H}$ bridges if required. Such devices operate by comparing the demanded voltage versus winding current on two phases, and control current in an analogue feedback loop from rotor position sensors. Although potentially a cheap solution, this option was not pursued as it was deemed unsuitable for larger automotive traction motors.

\section{Option $\mathrm{O} 2$}

A typical arrangement for $\mathrm{O} 2$ is shown in Figure 9. A centralised motor controller senses all three-phase currents and compares with the demanded torque from the vehicle control. Using a standard motor control algorithm [15], Motor Control sends information to each module to generate the appropriate voltage waveform.

The Data Bus sends duty cycle time from Motor Control to each module and the modules return their internal battery state of charge (SOC). A simple

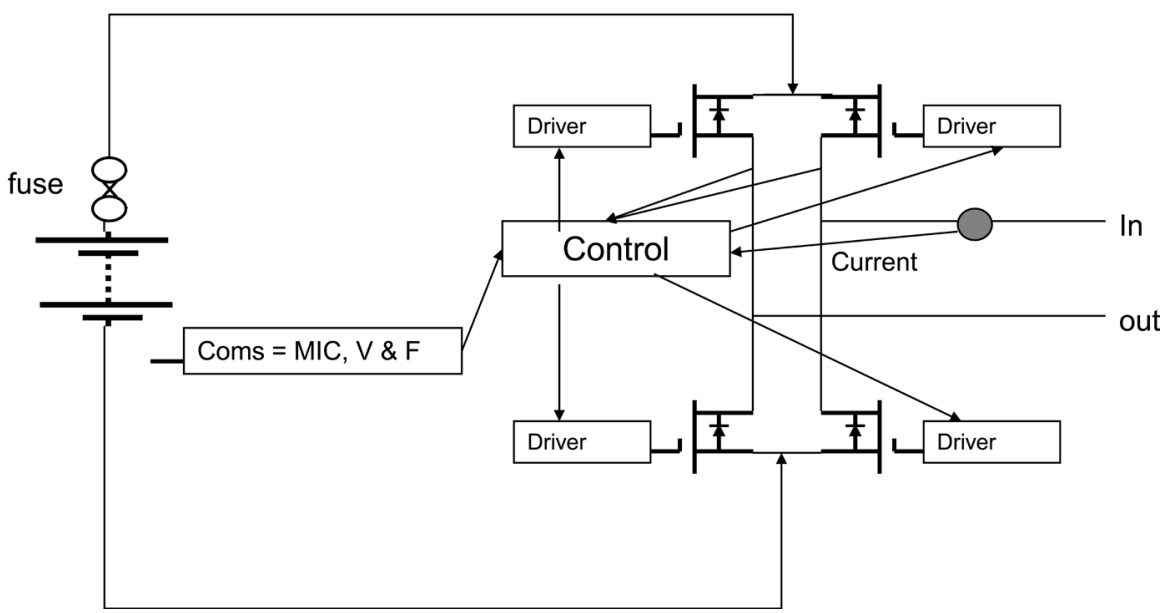

Figure 8. Option 1 module schematic.

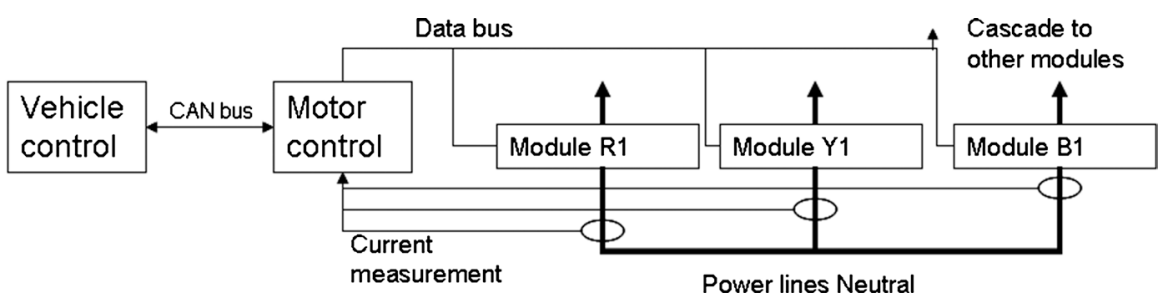

Figure 9. Option 2 configuration. 
Table 5. Costs for option 2 split into 8 and 16 cell derivatives.

\begin{tabular}{cccc}
\hline & & O2a & O2b \\
Description & & $\mathbf{1 6}$ cell & $\mathbf{8}$ cell \\
$\mu \mathrm{C}$ & Device & Cost & Cost \\
Opto isolator control & simple microchip & $£ 0.70$ & $£ 0.70$ \\
Full bridge PWM & EL3H7-G & $£ 0.13$ & $£ 0.13$ \\
MOSFET & LM5045 & $£ 1.78$ & $£ 1.78$ \\
i2c isolation & NVMFD5C446NL & & $£ 1.21$ \\
& NVMFS6H801N & $£ 2.68$ & \\
& ISO1542 & $£ 1.73$ & $£ 1.73$ \\
\hline & Components total & $£ 7.03$ & $£ 5.56$ \\
& PCB & $£ 0.50$ & $£ 0.50$ \\
& Assembly & $£ 0.50$ & $£ 0.50$ \\
& Misc & $£ 0.80$ & $£ 0.66$ \\
& Total & $£ 8.83$ & $£ 7.21$ \\
& \% target & $221 \%$ & $361 \%$ \\
\hline
\end{tabular}

microcontroller computes the SOC for each battery and communicates with the Motor Control via the Data Bus.

The system cost is compared with the targets computed earlier and as can be seen from Table 5, the 16 cell configuration is closest to the target but still $221 \%$ above target cost.

\section{Option $\mathrm{O3}$}

By incorporating all the control elements into each module and with common software, the motor control unit of Figure 9 can be removed to save cost. In this option we assume that a more powerful microcontroller can code coms signals using Manchester or similar techniques so that inter-module communications is via simple capacitor isolation, thus removing the need for expensive isolators as shown in Table 6. Again the 16-cell configuration is cheaper at $203 \%$ above target cost.

ASIC

The target EV market is very large making the viability of an application specific integrated circuit (ASIC) possible. An outline system drawing for an ASIC option is shown in Figure 10.

The ASIC would contain the MOSFET drivers, power supplies, battery management and encoding for the inter-module coms link via low-cost capacitors C4, C5, C6, each $1 \mathrm{nF}$ costs are shown in Table 7. The ASIC cost is based on confidential discussions with a large silicon IC supplier, based on their previous experience the $£ 1.50$ cost in very large volume quoted should be achievable. Indeed, large volume manufacturers can negotiate ASIC prices, so the figures below are likely to be an upper price bound. 
Table 6. Costs for option 3 split into 8 and 16 cell derivatives.

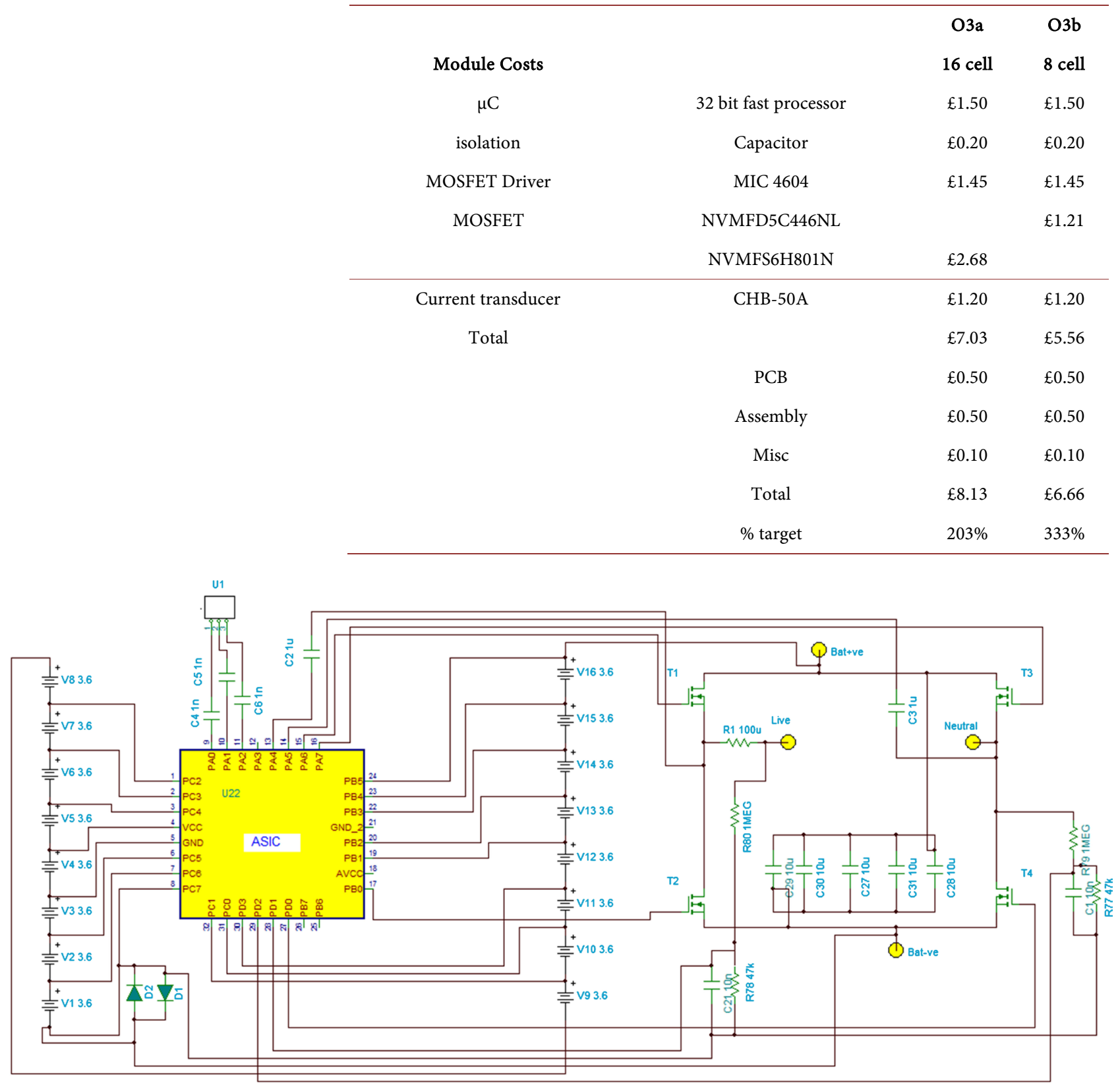

Figure 10. ASIC outline design.

The 16-cell design provides the lowest cost and is below the target. Additionally, all the individual cell management features are included, further reducing system cost. An outline ASIC design is shown in Figure 11 and was used to assess the ASIC cost.

\subsection{Heat Flow}

\subsubsection{MOSFETS}

Heat management calculations assume that the entire lower surface of the combined battery pack/PE assembly is made from $3 \mathrm{~mm}$ thick aluminium plate that 
Table 7. ASIC costs for 16 cell derivative.

\begin{tabular}{ccc}
\hline Module Costs & & ASIC \\
ASIC & & 16 cell \\
Isolation Capacitor & & $£ 1.50$ \\
Passives & & $£ 0.20$ \\
MOSFET & NVMFS6H801N & $£ 0.20$ \\
Total & & $£ 1.33$ \\
& PCB & $£ 3.23$ \\
& Assembly & $£ 0.30$ \\
& Misc & $£ 0.30$ \\
& Total & $£ 0.06$ \\
& \% target & $£ 3.89$ \\
& & $97 \%$
\end{tabular}

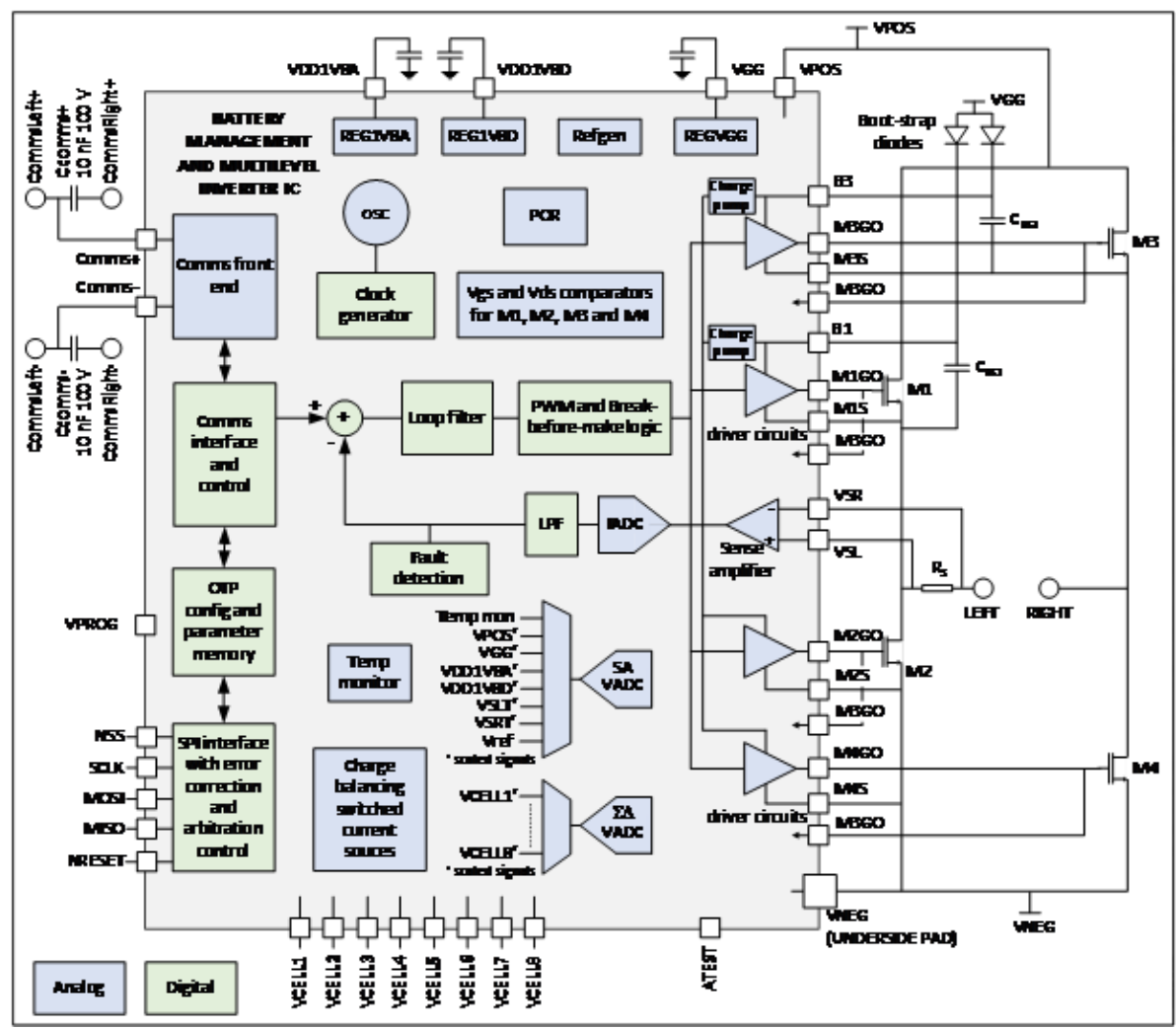

Figure 11. Outline ASIC design used for cost comparisons.

acts as both battery housing and a surface from which the heat is dissipated to ambient air. A reference air speed of $30 \mathrm{~m} / \mathrm{s}$ (near the speed limit on an up-hill motorway) is assumed in computing the convective thermal resistance from aluminium to ambient. It is assumed air is drawn through rectangular ducts of height $50 \mathrm{~mm}$ and width $300 \mathrm{~mm}$. For all MOSFETs a PCB copper track is added to the drain in a configuration shown in Figure 12 and H-Bridge placement in 
Figure 13. It is conservatively assumed that all the heat flow is passed via the metallised drain terminal (shown in grey, Figure 14) and none through the top of the package. The parameters used are: for the MOSFET $=$ NTMFS6H800N data sheet [16] and thermally conductive adhesive = AS1803 [17].

The four H-Bridge MOSFETs are shown in Figure 13, the grey areas are the metallised drain and black the epoxy case.

$$
T_{c f}=\text { thermal conductivity of the MOSFET epoxy case }=1.55 \mathrm{~W} / \mathrm{mK}
$$

This value is so close to the value for the thermally conducting silicone filler that it was assumed that the filler covers the entire underside, and hence the effect of Td was ignored.

Each copper square has an area of $2 \mathrm{~cm}^{2}$ and the aluminium plate $80 \times 40 \mathrm{~mm}$ with uniform air flow in the direction indicated by the arrows.

The thermal resistance from MOSFET to ambient is given by:

$$
R \theta_{d t o A}=R \theta_{d D c}+R \theta_{c f} R \theta_{D c}+R \theta_{d c a}+R \theta_{c f}+R \theta_{f A l}+R \theta_{A l A}
$$

\section{Side View}

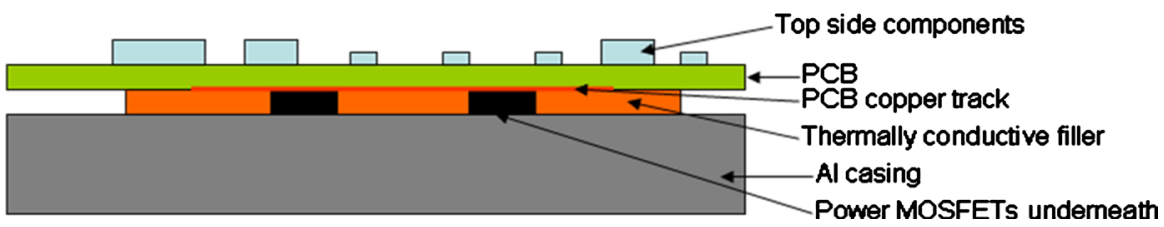

Figure 12. Physical component structure, showing heat flow elements (cross-section representation).

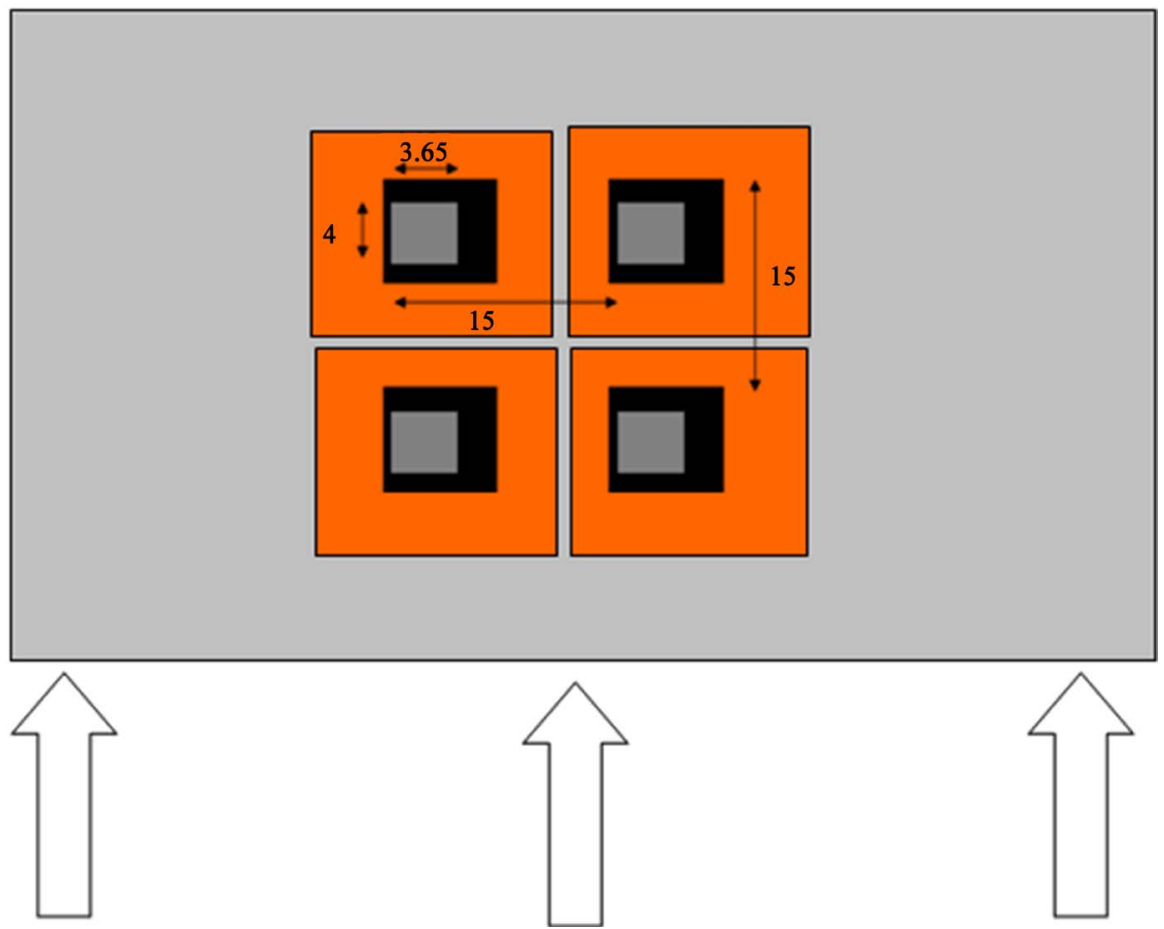

Figure 13. Transparent view of the H-Bridge layout of SO-8FL MOSFET packages. Dimensions shown are in $\mathrm{mm}$. 
where the thermal resistances are:

$R \theta_{d c a}$ device (junction) to case $=0.75^{\circ} \mathrm{C} / \mathrm{W}$ (from data sheet);

$R \theta_{c c a}$ average resistance from case to copper;

$R \theta_{c f}$ copper through filler, $R \theta_{f A l}$ filler to Aluminium plate and $R \theta_{A l A}$ is the convective thermal resistance from the aluminium plate to ambient.

At full power and $\mathrm{R}_{\text {on }}$ typical $=2.1 \Omega$ at 28 A average with $\dot{I}^{2} R=1.6 \mathrm{~W}$ th thermal per device gives $3.3 \mathrm{~W}$ th per H-bridge, (Wth = heat flow in Watts thermal.) with a junction temperature of $25^{\circ} \mathrm{C}$. At the working junction temperature $R_{o n}=$ $4.2 \Omega$ giving 6.6 Wth of heat.

where:

$W_{c u}=$ width of the copper layer $=70 \mu \mathrm{m}$;

$W_{a l}=$ width of aluminium casing $=3 \mathrm{~mm}$;

$A_{c u}=$ area of the copper underneath each MOSFET $=2 \mathrm{~cm}^{2}$.

Metal thermal resistances were evaluated using a worst-case approximation as shown in Figure 14.

The central grey area is assumed to be at a uniform temperature, and the arrows length $L$ show half the distance from this central region to the metal periphery.

$$
R \theta=\frac{0.25 L}{\rho W T}
$$

where $T$ is the metal thickness and $W$ is the width of the upper (grey) metal. The beneficial effects of the outer 4 squares are ignored, so there are 4 thermal paths in parallel hence the 0.25 constant.

For the copper layer $\rho \mathrm{Cu}=401 \mathrm{~W} / \mathrm{m} \cdot \mathrm{K}, L=1.675 \mathrm{~W}=4 T=0.075 \mathrm{~mm}$ giving

$$
R \theta_{c c a}=3.481 \mathrm{C} / \mathrm{W}
$$

For the filler layer, $\rho F=2 \mathrm{~W} / \mathrm{m} \cdot \mathrm{K}$.

$L=1, W=4 T=3 \mathrm{~mm}$ giving

$$
R \theta_{c f}=2.604 C / W
$$

and aluminium $\rho \mathrm{Al}=237 \mathrm{~W} / \mathrm{m} \cdot \mathrm{K}$.

$L=8, W=28 \mathrm{~T}=3 \mathrm{~mm}$ giving

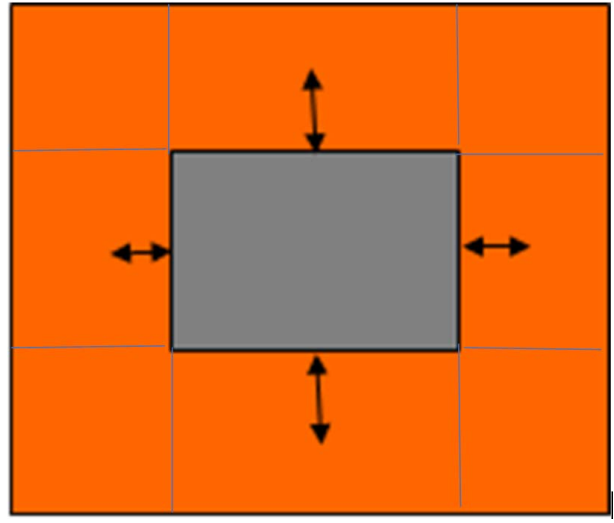

Figure 14. Heat flow approximation. 


$$
R \theta_{f A l}=0.1 C / W
$$

Thermal resistance from MOSFET junction to aluminium plate $=5.2 \mathrm{C} / \mathrm{W}$.

Thermal resistance from plate to air was computed assuming a duct with fully developed flow (being the worst-case condition). Input data is shown in Table 8 and results in Table 9.

At $30 \mathrm{~m} / \mathrm{s} \mathrm{h}=91.3 \mathrm{~W} / \mathrm{m}^{2} \mathrm{~K}$ and assuming the convective surface is a square of $40 \mathrm{~mm} \times 40 \mathrm{~mm}$,

$$
R \theta_{A l A}=6.85 C / W
$$

Total thermal resistance from junction to air is therefore $12 \mathrm{ClW}$ and with 6.6Wth gives a junction temperature of $139^{\circ} \mathrm{C}$ under the assumed worse case condition at $40^{\circ} \mathrm{C}$ ambient temperature. This is well within the maximum of $175^{\circ} \mathrm{C}$ quoted in the NTMFS6H800N data sheet.

\subsubsection{I-Bridge Completion Circuit}

Heat flow per device is given by:

$$
0.5 I_{a v} V C E_{s a t}
$$

Table 8. Duct input data used in computations.

\begin{tabular}{ccc}
\hline Duct height & 0.05 & $\mathrm{~m}$ \\
Duct width & 0.3 & $\mathrm{~m}$ \\
Duct area & 0.015 & $\mathrm{~m}^{2}$ \\
Duct perimeter & 0.7 & $\mathrm{~m}$ \\
Hydraulic diameter & 0.09 & $\mathrm{~m}$ \\
Air pressure & 101,325 & $\mathrm{~Pa}$ \\
Air temperature & 313 & $\mathrm{~K}$ \\
Air density & 1.13 & $\mathrm{~kg} / \mathrm{m}^{3}$ \\
Prantl no & 0.707 & \\
Viscosity & $1.85 \mathrm{E}-05$ & $\mathrm{Ns} / \mathrm{m}^{2}$ \\
Arc conductivity & 0.0263 & \\
\hline
\end{tabular}

Table 9. Results of air flow thermal analysis.

\begin{tabular}{cccc}
\hline Velocity, $\mathrm{m} / \mathrm{s}$ & $\mathrm{Re}$ & $\mathrm{NuD}$ & $\mathrm{W} / \mathrm{m}^{2} \mathrm{~K}$ \\
\hline 5 & 26,187 & 71 & 21.8 \\
10 & 52,374 & 124 & 37.9 \\
15 & 78,560 & 171 & 52.4 \\
20 & 104,747 & 215 & 66.0 \\
25 & 130,934 & 257 & 78.9 \\
30 & 157,121 & 298 & 91.3 \\
\hline
\end{tabular}

Where $\mathrm{Re}=$ Reynolds number; $\mathrm{NuD}=$ Nusselt number; $\mathrm{h}=$ the average thermal conductivity; using the Dittus Boelter [18] method. 
where VCEsat is the transistor saturation voltage at the average current $I_{a r}$

For the STGP15H60DF IGBT, this give a heat flow of $22.4 \mathrm{~W}$. As this would require a significant heat sink, and nullify some of the benefits of the concept, this option was not taken any further.

\subsection{Mass}

In order to make mass comparisons, the following assumptions were made:

1) Module interconnections were excluded as conventional systems also require battery interconnects.

2) Because the interconnections are dual function, current/heat spreader no allowance is made for heat management off the PCB.

3) PE aluminium casing (the passive heat sink) is excluded.

4) Battery management connections are excluded.

5) Only PCB and component masses are included.

A PCB for option O2a (the best non-ASIC solution) was built (this being typical of all the options) and weighed at $35 \mathrm{~g}$. A mock-up of an ASIC PCB weighed $5 \mathrm{~g}$. There are 10 modules per phase and 4 motors in the reference design giving 120 modules in total, the mass is shown in Table 10 and it can be seen that the ASIC solution is nearly 7 times lighter than the target and assuming air cooling.

\section{Results and Discussion}

\subsection{Cost and Mass}

A number of system configuration options were designed to compute overall costs and compared with the 2035 target costs to give a percentage of target as summarised in Table 11. Devices currently available for BEC tend to be cheaper for system voltages up to $40 \mathrm{~V}$ ( 8 cells), above that costs increase due to considerations in the basic silicon design. However, it is clear from the results that the reductions are insufficient to offset the increased number of modules required

Table 10. Mass comparison with target $(2035$ target $=50 \mathrm{~kW} / \mathrm{kg}$, number of modules $=$ 120).

\begin{tabular}{cccc}
\hline Item & Unit & Best non-ASIC & ASIC \\
\hline PCB module & $\mathrm{g}$ & 35 & 5 \\
Vehicle PE & $\mathrm{kg}$ & 4.2 & 0.6 \\
$\%$ target & & $105 \%$ & $15 \%$ \\
\hline
\end{tabular}

Table 11. Cost summary across options.

\begin{tabular}{ccc}
\hline \multicolumn{3}{c}{ Cost relative to 2035 target } \\
\hline O2 & 16 Cell & $\mathbf{8}$ cell \\
O3 & $203 \%$ & $333 \%$ \\
ASIC & $221 \%$ & $361 \%$ \\
\hline
\end{tabular}


for the lower voltage modules. In all cases the 16-cell option gives the cheaper overall system cost.

ASIC

In the ASIC option, the PCB and assembly costs are reduced as the components are minimal so saving costs. In addition, the ASIC contains all the BMS circuitry further reducing system costs below and beyond the 2035 cost targets.

\subsection{General Discussion}

So far, this paper has concentrated on the impact of $\mathrm{CHB}$ on the vehicle. $\mathrm{CHB}$ has many other benefits external to the vehicle; under certain circumstances, battery charging can be from single or three-phase mains, DC low impedance source (for example a fast charger) and Photovoltaic arrays (PV) [19]. There is also considerable interest in using vehicle batteries for mains grid stabilisation [20].

If the minimum battery voltage is greater than the peak mains voltage and the CHB is synchronised with the mains, then batteries can be charged with single or three-phase supplies without the need for additional chargers. In addition, if the software includes MPPT algorithms, then batteries can be charged directly from PV cells as long as the PV array voltage is higher than an individual module voltage.

Wide use of CHB would then remove the need for external chargers and enable more rapid adoption in developing countries where mains supplies are sporadic but there is plenty of sunlight for PV vehicle charging. These country wide cost reductions would make a significant contribution to EV uptake.

This paper has only concentrated on traction control of EV motors, vehicle also has to power ancillaries. There are many techniques available to do this but are outside the scope of this paper.

\section{Conclusions}

Electric Vehicles are seen as a major contributor to reducing carbon emissions and hence global warming. The Power ElectronicsUK Automotive Challenge road map outlines reductions in cost and mass for the power electronics that control EV motors as on driver for longer range and hence quickening EV uptake. This paper has shown that from a cost and mass perspective of the vehicle alone, $\mathrm{CHB}$ can meet the 2035 targets with a special ASIC. Design houses quote about 18 months to 2 years to make prototype ASICs, meaning that a solution could be available in 2023 if funds were made available, 12 years earlier than the target date. Additionally, vehicle installation is simpler due to passive cooling, $\mathrm{EV}$ range is increased due to the higher efficiency of $\mathrm{CHB}$ and power electronics in external charging facilities are not required reducing off-vehicle costs by more than an order of magnitude.

The paper shows that the new topology itself reduces mass and cost becoming even more beneficial when the effects of cooling systems are removed. 


\section{Acknowledgements}

We thank The Power Electronics UK Automotive Challenge network funded by EPSRC for this work through the BIPED feasibility study.

\section{Conflicts of Interest}

The authors declare no conflicts of interest regarding the publication of this paper.

\section{References}

[1] Paul Taylor. Power Electronics UK n.d. https://www.power-electronics.org.uk

[2] Chang, F., Ilina, O., Lienkamp, M. and Voss, L. (2019) Improving the Overall Efficiency of Automotive Inverters Using a Multilevel Converter Composed of Low Voltage Si Mosfets. IEEE Transactions on Power Electronics, 34, 3586-3602. https://doi.org/10.1109/TPEL.2018.2854756

[3] Mukherjee, N. and Tricoli, P. (2015) A State-of-Charge Equalisation Technique of Super-Capacitor Energy Storage Systems Using Sub-Module DC-DC Converter Control within Modular Multilevel Converter (MMC) for High Speed Traction Drive Applications. 50th International Universities Power Engineering Conference (UPEC), Stoke on Trent, 1-4 September 2015, 1-6. https://doi.org/10.1109/UPEC.2015.7339948

[4] Quraan, M., Yeo, T. and Tricoli, P. (2016) Design and Control of Modular Multilevel Converters for Battery Electric Vehicles. IEEE Transactions on Power Electronics, 31, 507-517. https://doi.org/10.1109/TPEL.2015.2408435

[5] Davidson, C.C. and Trainer, D.R. (2011) Innovative Concepts for Hybrid Multi-Level Converters for HVDC Power Transmission. 9 th IET International Conference on $A C$ and DC Power Transmission, London, 19-21 October 2010, 1-5. https://doi.org/10.1049/cp.2010.0982

[6] Tolbert, L.M., Peng, F.Z. and Habetler, T.G. (1999) Multilevel Converters for Large Electric Drives. IEEE Transactions on Industry Applications, 35, 36-44. https://doi.org/10.1109/28.740843

[7] Tolbert, L.M., Peng, F.Z., Cunnyngham, T. and Chiasson, J.N. (2002) Charge Balance Control Schemes for Cascade Multilevel Converter in Hybrid Electric Vehicles. IEEE Transactions on Industrial Electronics, 49, 1058-1064. https://doi.org/10.1109/TIE.2002.803213

[8] Chang, F., Zheng, Z. and Li, Y. (2014) PWM Strategy of a Novel Cascaded Multi-Level Converter for Battery Management. 17 th International Conference on Electrical Machines and Systems (ICEMS), Hangzhou, 22-25 October 2014, 3208-3212. https://doi.org/10.1109/ICEMS.2014.7014045

[9] Du, Z., Ozpineci, B., Tolbert, L.M. and Chiasson, J.N. (2009) DC-AC Cascaded H-Bridge Multilevel Boost Inverter with No Inductors for Electric/Hybrid Electric Vehicle Applications. IEEE Transactions on Industry Applications, 45, 963-970. https://doi.org/10.1109/TIA.2009.2018978

[10] Hohm, D.P. and Ropp, M.E. (2003) Comparative Study of Maximum Power Point Tracking Algorithms. Progress in Photovoltaics. Research and Applications, 11, 47-62. https://doi.org/10.1002/pip.459

[11] Ye, Z. and Pilawa-Podgurski, R.C.N. (2016) A Power Supply Circuit for Gate Driver of GaN-Based Flying Capacitor Multi-Level Converters. IEEE 4th Workshop on 
Wide Bandgap Power Devices and Applications, Fayetteville, 7-9 November 2016, 53-58. https://doi.org/10.1109/WiPDA.2016.7799909

[12] Timothe, S., Nicolas, R., Jean-Christophe, C. and Jean-Daniel, A. (2011) Design and Characterization of a Signal Insulation Coreless Transformer Integrated in a CMOS Gate Driver Chip. 2011 IEEE 23rd International Symposium on Power Semiconductor Devices and ICs, San Diego, 23-26 May 2011, 360-363.

https://doi.org/10.1109/ISPSD.2011.5890865

[13] Jasielski, J. and Kuta, S. (2018) Applied Methods of Power Supply and Galvanic Isolation of Gate Drivers of Power Transistors in Bridging end Stages of Class D Amplifiers and Inverters. Science, Technology and Innovation, 2, 31-41. https://doi.org/10.5604/01.3001.0012.1413

[14] Nguyen, V.S., Lefranc, P. and Crebier, J.C. (2018) Gate Driver Supply Architectures for Common Mode Conducted EMI Reduction in Series Connection of Multiple Power Devices. IEEE Transactions on Power Electronics, 33, 10265-10276. https://doi.org/10.1109/TPEL.2018.2802204

[15] Nakao, N. and Akatsu, K. (2016) Vector Control Specialized for Switched Reluctance Motor Drives. Electrical Engineering in Japan, 194, 24-36. https://doi.org/10.1002/eej.22776

[16] Semiconductors O. NTMFS6H800N DataSheet n.d. https://www.onsemi.com/PowerSolutions/product.do?id=NTMFS6H800N

[17] Silicones A. AS1803 Thermally Conductive Adhesive n.d. https://docs-emea.rs-online.com/webdocs/0b64/0900766b80b644dd.pdf

[18] Dittus, F.W. and Boelter, L.M.K. (1985) Heat Transfer in Automobile Radiators of the Tubular Type. International Communications in Heat and Mass Transfer, 12, 3-22. https://doi.org/10.1016/0735-1933(85)90003-X

[19] Vavilapalli, S., Umashankar, S., Sanjeevikumar, P., Ramachandaramurthy, V.K., Mihet-Popa, L. and Fedák, V. (2018) Three-Stage Control Architecture for Cascaded H-Bridge Inverters in Large-Scale PV Systems-Real Time Simulation Validation. Applied Energy, 229, 1111-1127. https://doi.org/10.1016/j.apenergy.2018.08.059

[20] Yu, M., Huang, W., Tai, N., Zheng, X., Wu, P. and Chen, W. (2018) Transient Stability Mechanism of Grid-Connected Inverter-Interfaced Distributed Generators Using Droop Control Strategy. Applied Energy, 210, 737-747.

https://doi.org/10.1016/j.apenergy.2017.08.104 